\title{
TERRAIN AND LABORATORY CONDUCTIVITY STUDIES OF FLOOD PLAINS OF OLUWATUYI/OSHINLE AREAS OF AKURE
}

\author{
M. I. OLADAPO AND M. A. ISOGUN \\ (Received 30, September 2004; Revision Accepted 20, January 2005)
}

\begin{abstract}
A shallow electromagnetic study (electrical conductivity and magnetic susceptibility measurements) and laboratory conductivity sampling of the flood plains of Oluwatuyi/Oshinle area of Akure have been undertaken. This is with the aim of correlating the terrain conductivity mapping with laboratory measurements to establish the effectiveness of the induced secondary currents in determining the effects of infiltrating leachates occasioned by heaps of refuse dumped in the course of River Elegbin in the study area.

Quadrature and in-phase measurements in vertical and horizontal dipole modes were undertaken on seventeen traverses of various lengths. Laboratory conductivity measurements were conducted on twenty one water samples obtained from hand-dug wells.

The horizontal dipole measurements exhibit higher conductivity values suggesting contamination of the upper strata from the ubiquitous refuse in the area. The lower conductivity values obtained from the vertical dipole mode may be due to the high retarding capability of abundant clay in the area to contaminant flow. The similarity in conductivity distribution obtained from field and laboratory studies show that terrain conductivity is strongly influenced by saturating fluid.

The high magnetic susceptibility values obtained in northern course of the river suggests predominantly ferromagnetic dumps while the low values characterizing the central and southern course indicate predominantly domestic waste in the zone.
\end{abstract}

KEYWORDS: Terrain and laboratory conductivity studies, refuse dumps, infiltrating leachates, magnetic susceptibility, ferromagnetic dumps and domestic waste.

\section{INTRODUCTION}

Dealing with contaminated site is a major problem in urban areas because conventional site characterization typically involves intensive field programmes of drilling and core sampling, downhole geophysical logging, well monitoring, and hydrochemical analysis. Effective characterization of urban sites with elaborate field programmes is usually inhibited by limited available space to work and the presence of ambient electrical noise. Site characterization in such urban centres can be rapidly and perhaps effectively implemented with the use of shallow electromagnetic field study. Chief among the reasons for utilizing shallow electromagnetic method especially in urban areas is the ability of the method to work around the limitations. The instrument used in this study has been designed to enable movement and measurement in built-up areas.

Green et al (1999) included the terrain conductivity method (using EM-31 system) in the characterization of a landfill near the village of Stetten in northern Switzerland. Higher conductivities in the study area were attributed to waste materials while low conductivities were attributed to higher gravel and sand content. The method adopted in this study was also utilized by Lanz et al (1998) to carry out a geophysical investigation on landfill delineation and characterization. The study results were inverted to yield shallow electrical conductivities and approximate estimates of magnetic susceptibility that successfully delineated two distinct wastes separated by a $20-40 \mathrm{~m}$ wide zone of undisturbed ground. An environmental site investigation of former oil distribution terminals was also carried out by Vickery and Hobins (1998). The geophysical survey involved the use of Geonics EM-31 and Geonic 9896 magnetometer in gradient mode. The full detailed electromagnetic survey revealed a labyrinth of subsurface pipes about $1 \mathrm{~m}$ deep together with a number of anomalously low conductivity regions.

The relative ease of data collection gives EM a distinct advantage over conventional electrical resistivity profiling. The EM-31 instrument measures the apparent conductivity of the soil to a depth of approximately $20 \mathrm{ft}$ $(6 \mathrm{~m})$ by utilizing the principles of electromagnetic induction (Foster et al, 1987).

River Elegbin is one of the major rivers in Akure metropolis and it drains the southern half of the city into Owena River (Fig.1). The river has its source from some springs at Oshinle and ljoka in the southeastern area of Akure, running west through Oke-Aro to Isinkan quarters. Waste management schemes are not usually effective in high density areas of urban areas; hence in this case, the river course is being used as refuse dumps with the assumption that the refuse so dumped will be swept away by the flowing river. However, the refuse has impeded smooth flow of the river thereby resulting in flooded plains within Oluwatuyi and northern flank of Oshinle. The refuse has been stagnated on the flood plains thereby enabling leachates from the dump to infiltrate the surrounding soils. The infiltrating leachates constitute health hazards to the groundwater 
which serves as source of water supply to the residents of the areas adjoining the river bank.

The objective of this study is to determine the likely effect (on the shallow subsurface) of the infiltrating leachates from decaying wastes overlying the flood plains of Oluwatuyi/Oshinle areas. The study is also aimed at determining the influence of groundwater conductivity on the terrain conductivity.
GEOLOGY AND GEOMORPHOLOGY OF THE STUDY AREA

The study area covers Oluwatuyi and northern areas of Oshinle on the southeastern area of Akure. Akure lies within latitudes $7^{\circ} 13^{\prime} \mathrm{N}$ and $7^{\circ} 17^{\prime} \mathrm{N}$ and longitudes $5^{\circ} 09^{\prime} \mathrm{E}$ and $5^{\circ} 14^{\prime} \mathrm{E}$ (Fig. 1).

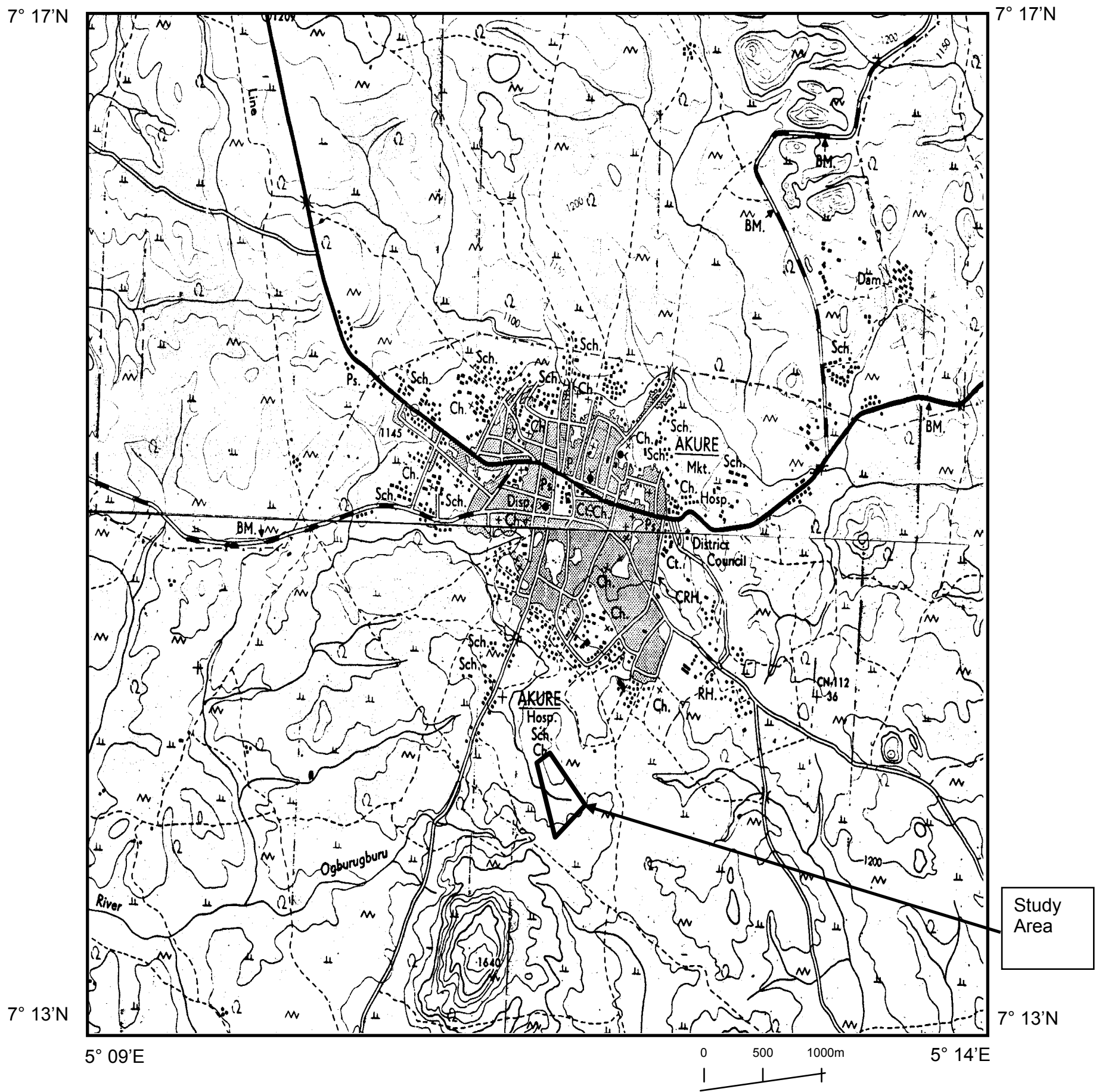

Fig. 1: Topographical map of Akure showing the study area 


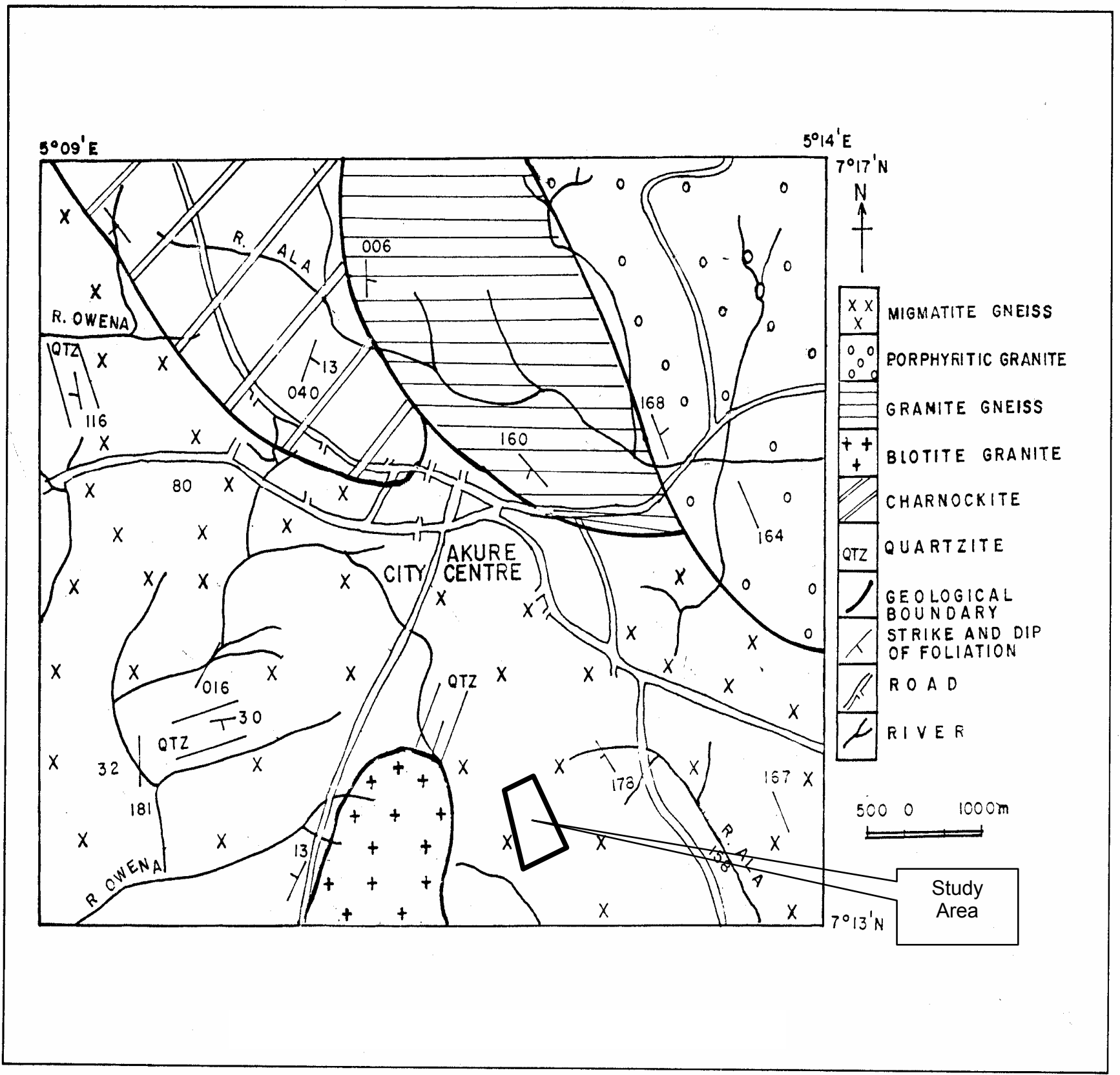

Fig. 2: Updated geological map of Akure (Owoyemi, 1996)

\section{METHODS OF STUDY}

The terrain conductivity study of Oluwatuyi/Oshinle area of Akure involved the use of the Geonic EM-31 conductivity meter. The laboratory study involves conductivity sampling of water obtained from hand-dug wells in the area. Seventeen traverses of variable lengths $(80 \mathrm{~m}$ to $580 \mathrm{~m}$ ) with station interval of $20 \mathrm{~m}$ were established within the study area (Fig. 3). Laboratory electrical conductivity measurements were carried out on 21 hand-dug well water samples in the area.

The EM-31 instrument operates with a fixed source-receiver separation of $3.66 \mathrm{~m}$ and a single frequency of $9.8 \mathrm{KHz}$. It measures in the vertical and horizontal dipole modes with depth penetration of about $6 \mathrm{~m}$ and $3 \mathrm{~m}$ respectively. The quadrature and in-phase give terrain conductivity in $\mathrm{mS} / \mathrm{m}$ and magnetic susceptibility in ppt respectively. 


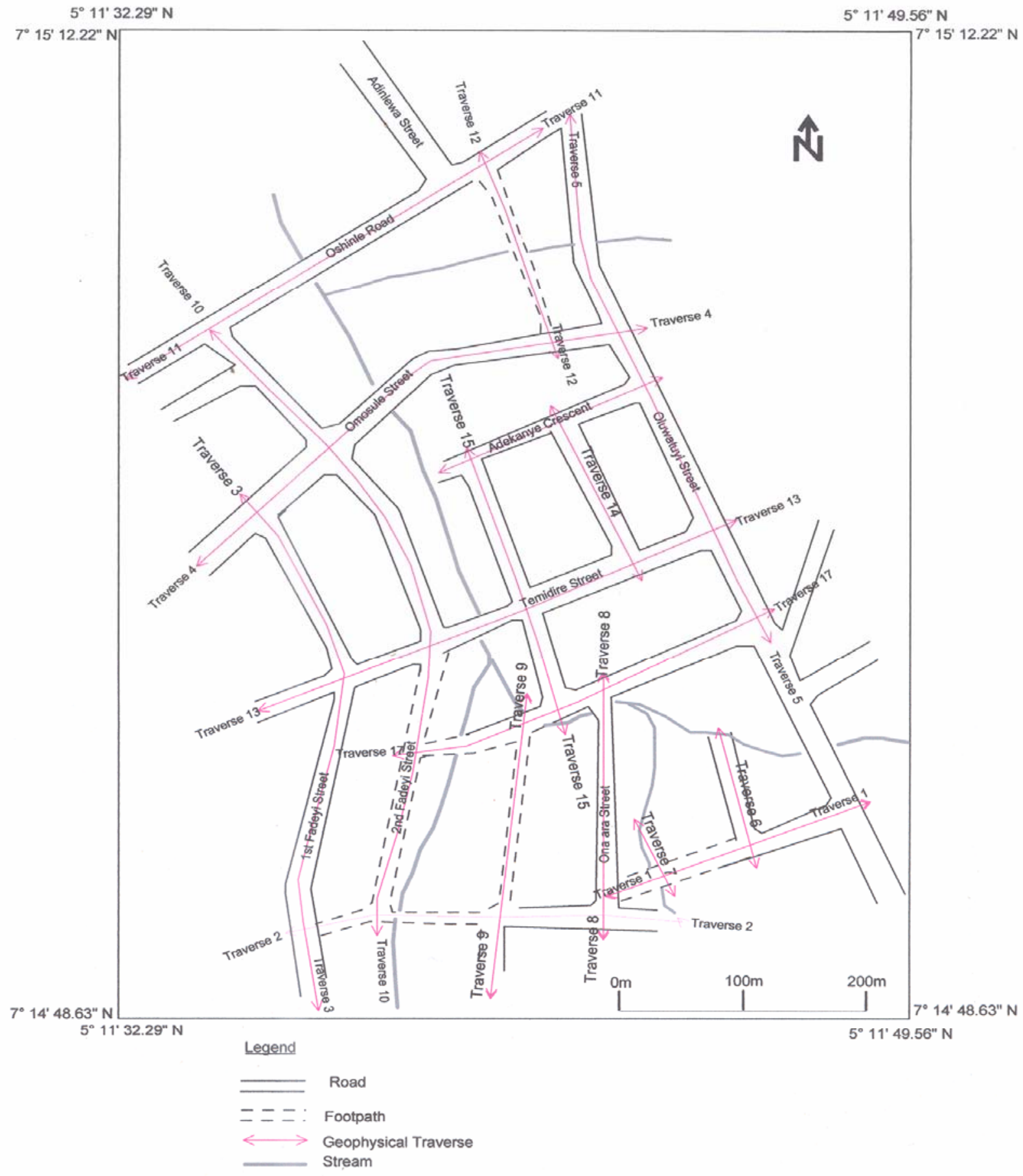

Fig. 3: Layout map of Study Area showing geophysical traverses.

\section{RESULTS AND DISCUSSION}

The results of this study are presented as maps (terrain conductivity, magnetic susceptibility and water conductivity maps) (Figs 4 to 8). The maps were developed with GEOSOFT and SURFER Version 6 application softwares.
Fig. 4 is the electrical conductivity map for horizontal dipole quadrature response. The southeastern part of the area shows electrical conductivity of $5 \mathrm{mS} / \mathrm{m}$ to $145 \mathrm{mS} / \mathrm{m}$. In the southeastern flank, the quadrature conductivity profiles increase eastwards where some springs exist. The southwestern part of the area is typified with conductivity 
values ranging from $10 \mathrm{mS} / \mathrm{m}$ to $60 \mathrm{mS} / \mathrm{m}$ with values increasing westwards. The northern half of the area is characterized by conductivity range of $20 \mathrm{mS} / \mathrm{m}$ to 80
$\mathrm{mS} / \mathrm{m}$. The river course is also characterized by low conductivity values at the central portions of the study area.

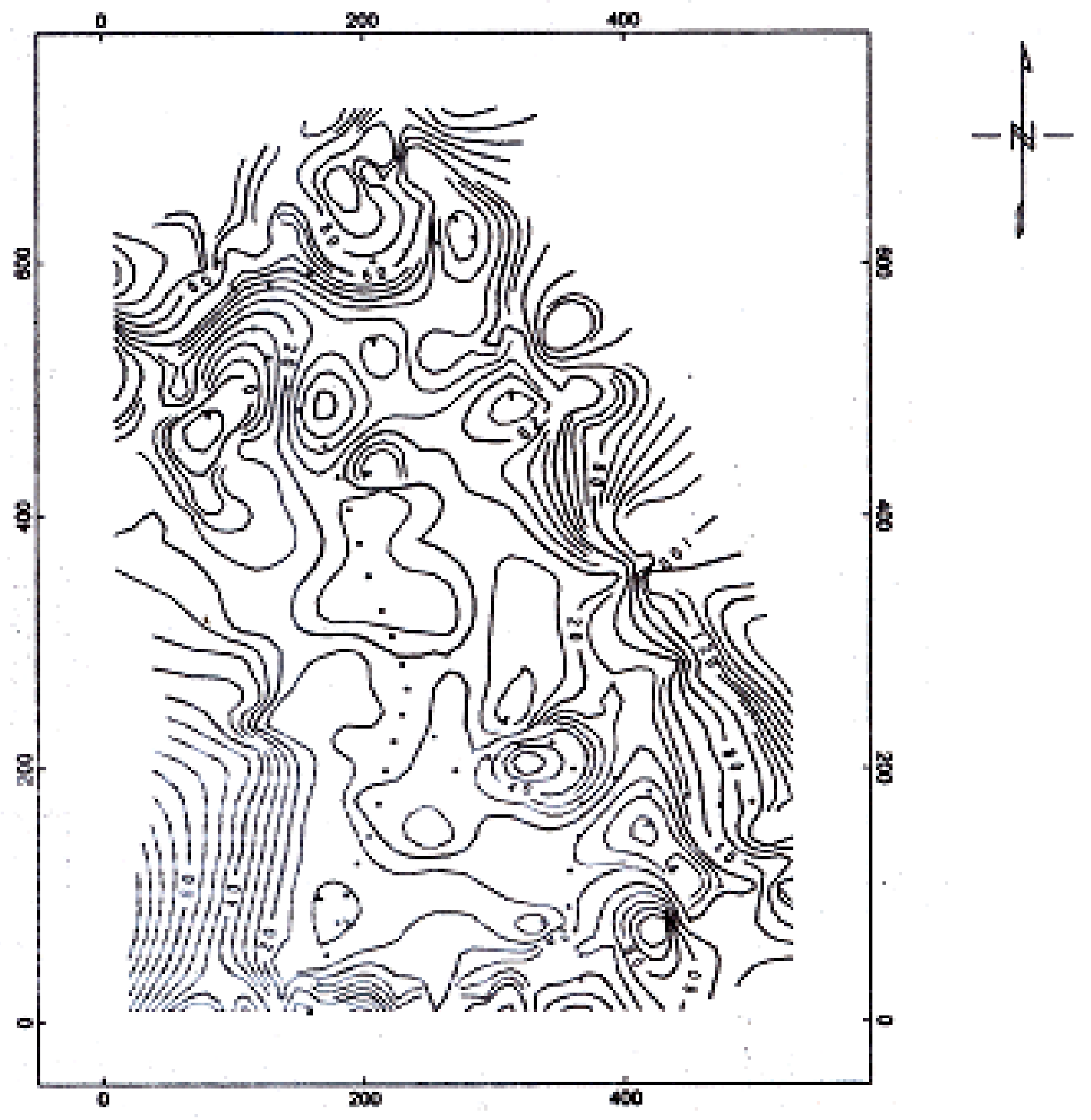

\section{LEGEND}

CONTOUR INTERVAL : $5 \mathrm{~ms} / \mathrm{m}$

$\ldots$ STREAM

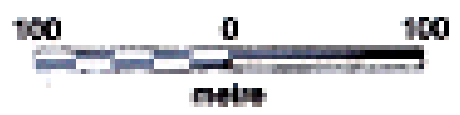

Fig. 4 Horizontal dipole quadrature map 


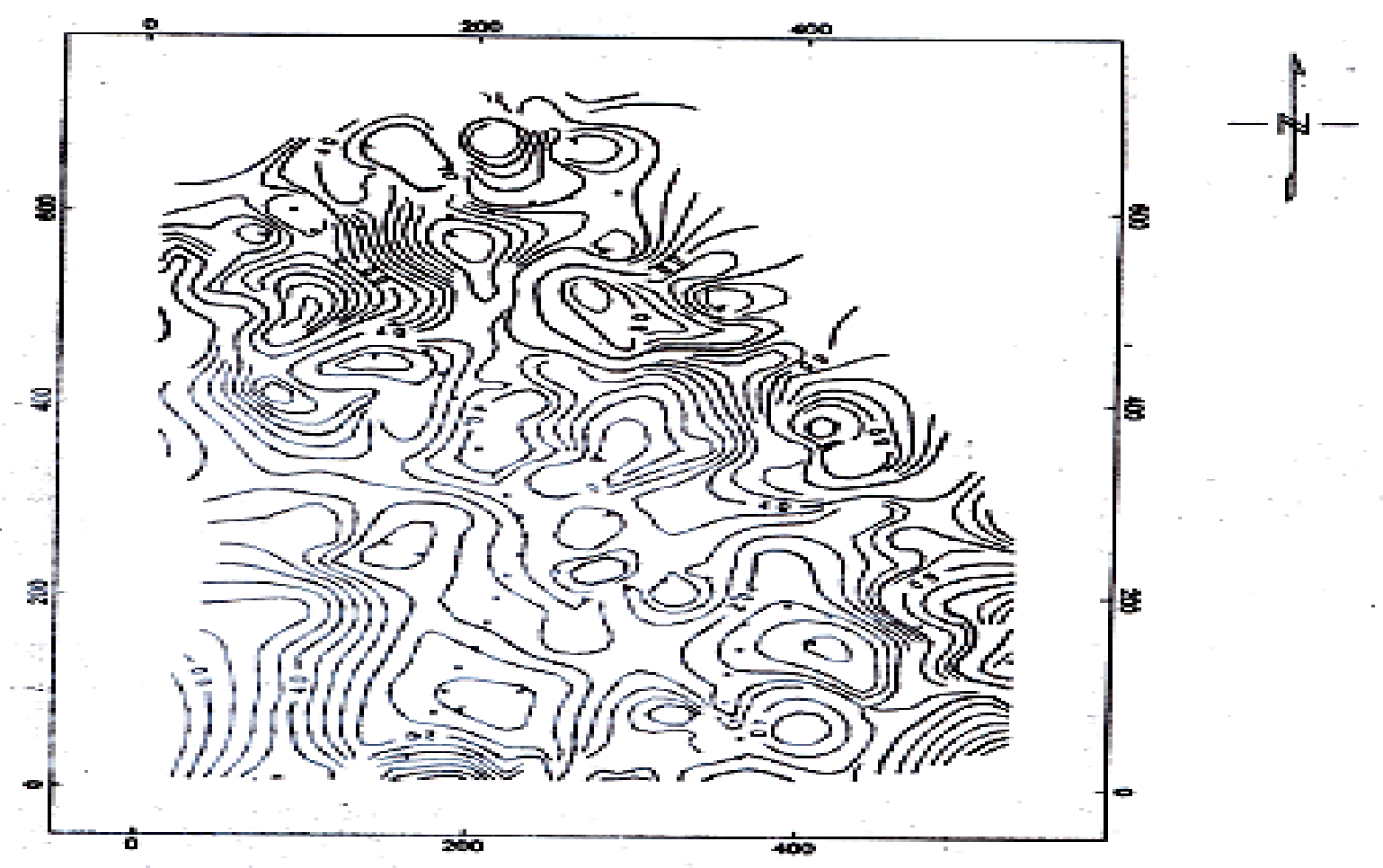

\section{LEGEND}

CONTOUF INTERNAL: $5 \mathrm{~ms} / \mathrm{m}$

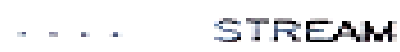

100

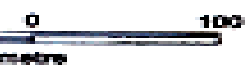

Fig. 5: Vertical dipole quadrature map

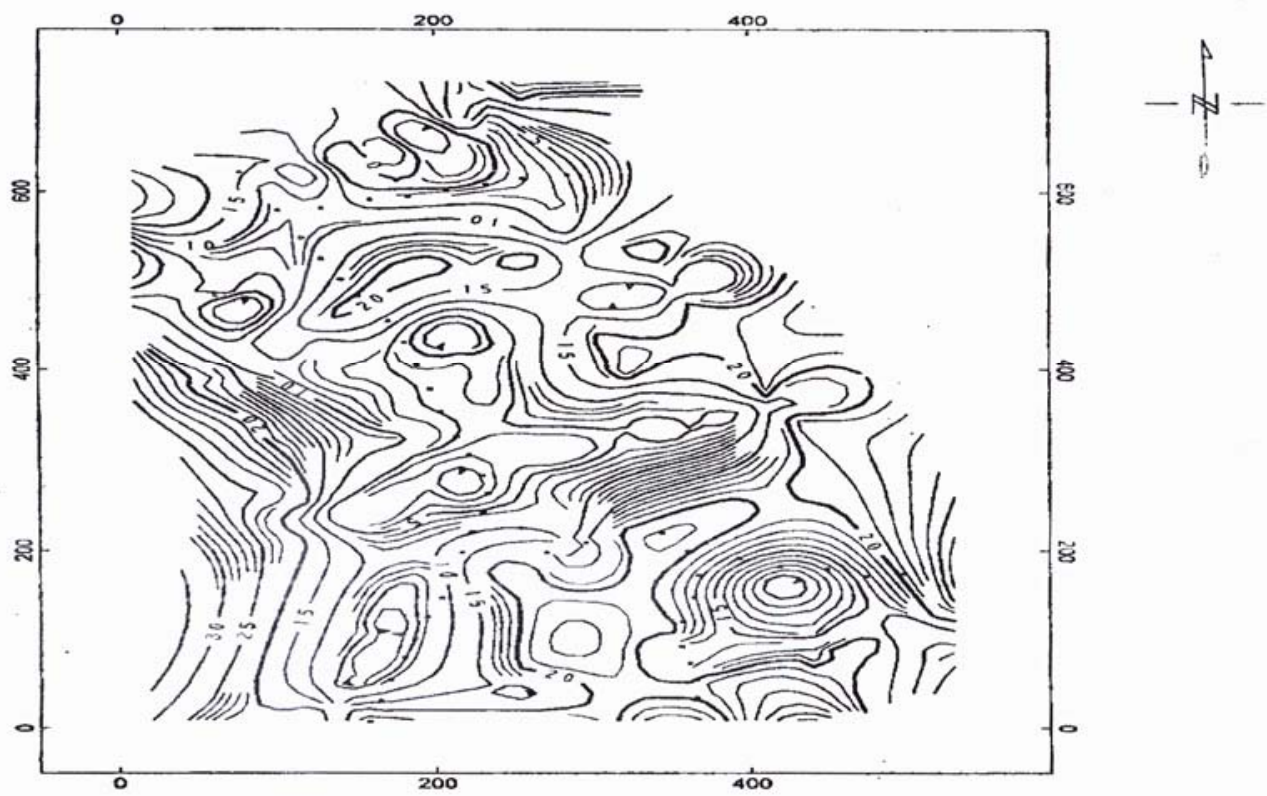

LEGEND

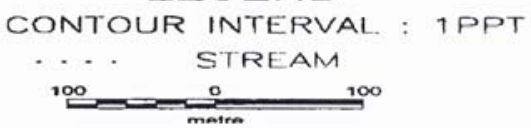

Fig. 6: Horizontal dipole in-phase map 


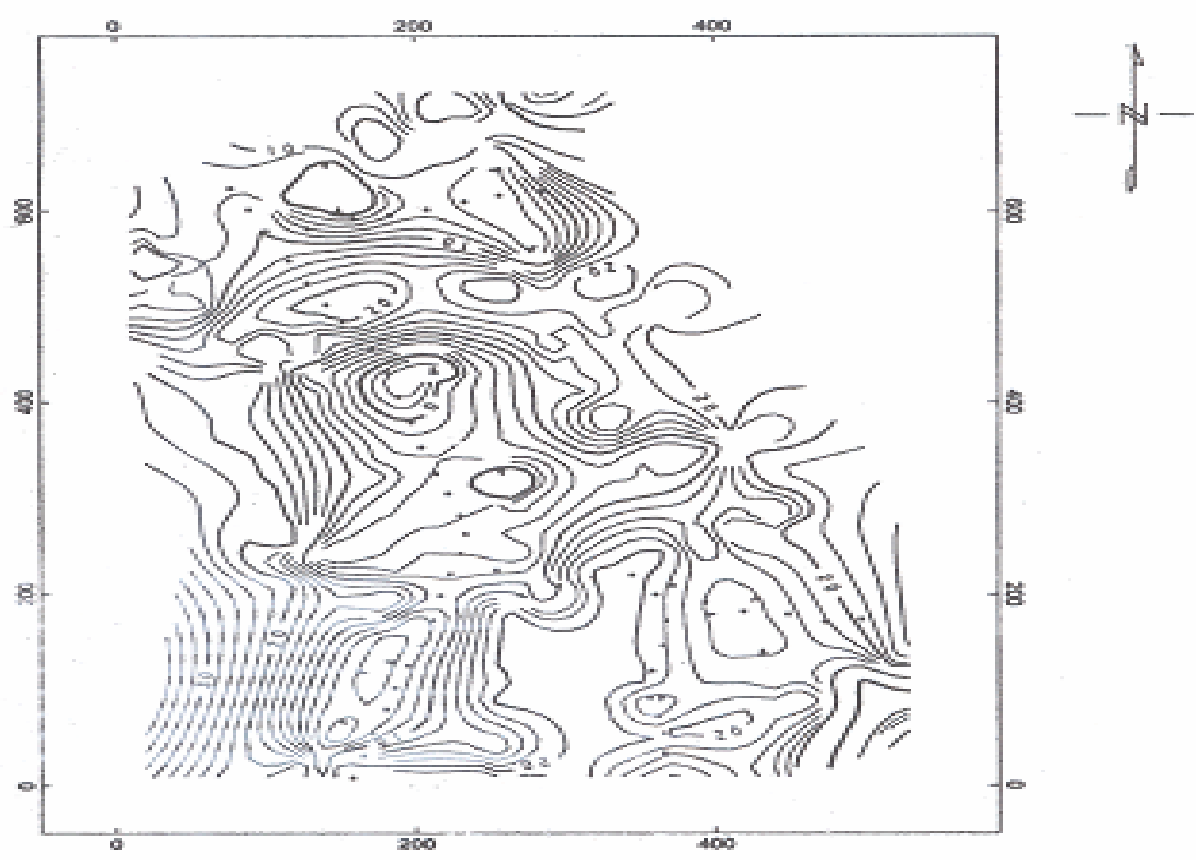

\section{LEGEND}

CONTOUR INTERVAL : 2 PPT

.... STREAM

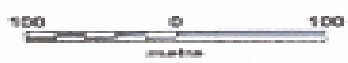

Fig. 7: Vertical dipole in-phase map

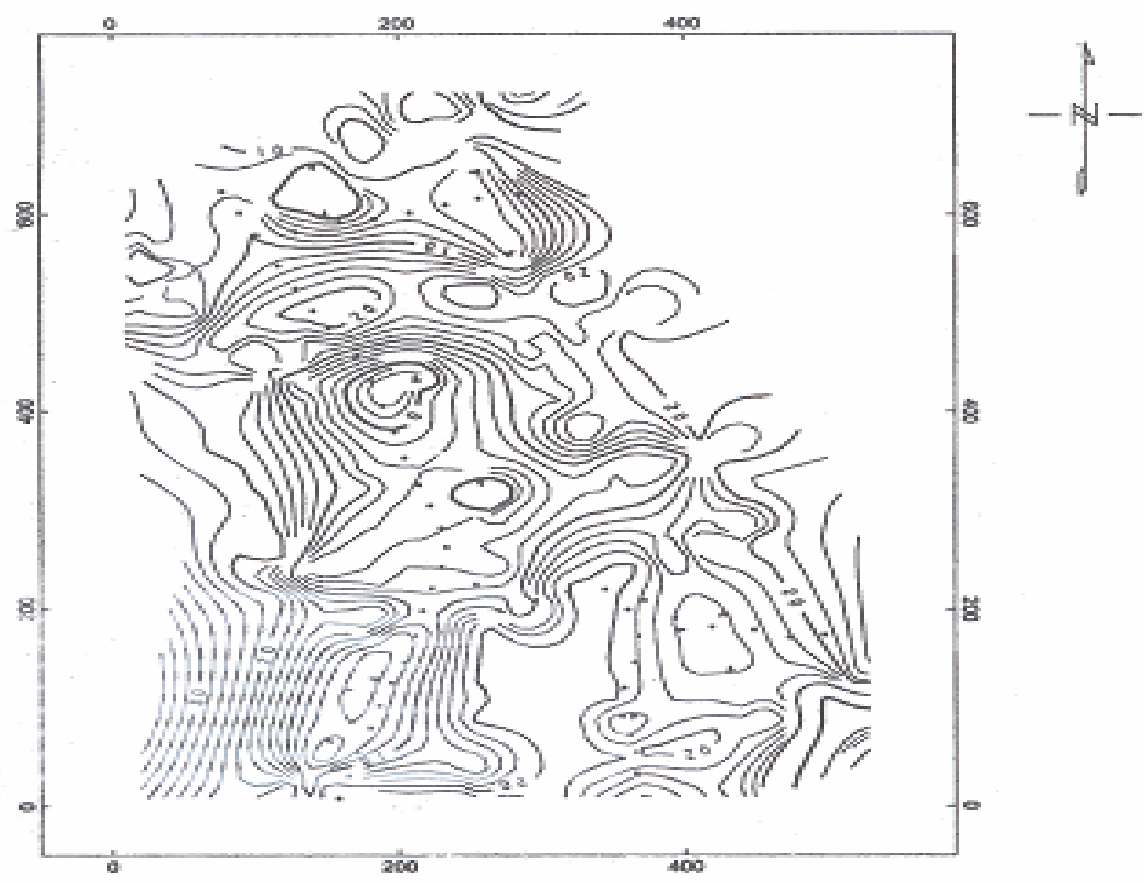

LEGEND

CONTOUR INTERVAL : 2 PPT

... STREAM

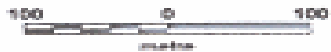

Fig. 8: Laboratory derived (water samples) conductivity map 
Fig. 5 is the electrical conductivity map for vertical dipole quadrature response. Conductivity values in the southeastern segment of the study area are lower than those obtained in the horizontal dipole mode of Fig. 4. Conductivity range of $20 \mathrm{mS} / \mathrm{m}$ to $60 \mathrm{mS} / \mathrm{m}$ was obtained in the south central parts while a range of 10 $\mathrm{mS} / \mathrm{m}$ to $65 \mathrm{mS} / \mathrm{m}$ was obtained on the southwestern end. The northern half of the area show conductivity range of $25 \mathrm{mS} / \mathrm{m}$ to $60 \mathrm{mS} / \mathrm{m}$. Along the river course, the conductivity steadily increased from $15 \mathrm{mS} / \mathrm{m}$ in the south (low values) to $60 \mathrm{mS} / \mathrm{m}$ in the north.

Fig. 6 is the magnetic susceptibility map for horizontal in-phase response. The southeastern part of the area is characterized by magnetic susceptibility values ranging from $10 \mathrm{ppt}$ to $25 \mathrm{ppt}$ and in the southwestern part by values ranging from 5 ppt to 35 ppt. The northern half of the area exhibit magnetic susceptibility values of between 5 ppt and 20 ppt. Along the river course, the magnetic susceptibility are generally low between $2 \mathrm{ppt}$ and $15 \mathrm{ppt}$.

Fig. 7 is the magnetic susceptibility map for vertical in-phase response. Low magnetic susceptibility characterizes the southeastern part of the area with values ranging from $14 \mathrm{ppt}$ to $20 \mathrm{ppt}$. In the southwestern part, the magnetic susceptibility values are higher with values ranging from $20 \mathrm{ppt}$ to $36 \mathrm{ppt}$. The northern half of the area shows lower magnetic susceptibility range of $10 \mathrm{ppt}$ to $20 \mathrm{ppt}$. The river course at the central area is generally characterized by low magnetic susceptibility values of $4 \mathrm{ppt}$ and $8 \mathrm{ppt}$.

Fig. 8 is the electrical conductivity map generated from laboratory conductivity measurement of water samples obtained from hand-dug wells in the area. The map shows conductivity values ranging from $0.17 \mathrm{mS} / \mathrm{m}$ to $0.65 \mathrm{mS} / \mathrm{m}$ in the southeastern part with increasing values towards the eastern flank. The southwestern part of the area is characterized by conductivity values ranging from $0.18 \mathrm{mS} / \mathrm{m}$ to 0.40 $\mathrm{mS} / \mathrm{m}$. The northeastern part of the map shows a conductivity range of $0.20 \mathrm{mS} / \mathrm{m}$ and $0.70 \mathrm{mS} / \mathrm{m}$ with an increasing trend along northeastern direction. The extreme northern part of the area is typified by conductivity range of between $0.24 \mathrm{mS} / \mathrm{m}$ and 0.54 $\mathrm{mS} / \mathrm{m}$ with steady increase towards the north.

\section{Implications of Electrical Conductivity Variations and their Significance in Environmental Impact of Refuse Dump}

Areas characterized by relatively high conductivity values $(>15 \mathrm{mS} / \mathrm{m})$ are the eastern and western flanks of River Elegbin. The relatively high values may be due to the combination of leachates from overlying refuse and clay/sandy clay superficial soils underlying the environment. The presence of refuse and the associated leachate is expected to contribute significantly to conductivity values measured at shallow levels. Thus superficial soils in such environment may locally exhibit higher conductivity at upper layers. The falling profile of conductivity values with depth in the area of study thus suggests contamination of the upper strata from the ubiquitous refuse in the area. The lower conductivity values obtained from the vertical dipole mode is presumably due to the high retarding capability of clay to contaminant flow. Clay horizons play an important role in the hydrogeology of an area by sealing off the surface contaminated water from the subsurface groundwater (Olorunfemi and Olorunniwo, 1985). The higher the percentage of clay content, the higher the groundwater protection in the environment. Also, areas characterized by low electrical conductivity $(<15 \mathrm{mS} / \mathrm{m})$ could be indicative of a near surface basement or sand/gravel.

In general, there is a good correlation in the values of the electrical conductivity and magnetic susceptibility of the area. Areas with high conductivity values $(20 \mathrm{mS} / \mathrm{m}$ to $100 \mathrm{mS} / \mathrm{m})$ show high magnetic susceptibility values (10 ppt to $20 \mathrm{ppt}$ ) and areas with low conductivities $(<20 \mathrm{mS} / \mathrm{m})$ show low magnetic susceptibility values (<10 ppt).

\section{Implications of Magnetic Susceptibility Variation and their Significance in Refuse Dump Classification}

Variations in the magnetic susceptibility contours (Figs. 6 and 7) can aid in the classification of refuse into ferromagnetic (metallic drums, cans, tins and waste metals) and non-ferromagnetic (domestic type trash) wastes. Magnetic susceptibility values are generally low on the southern network of spring sources of River Elegbin, thus few ferromagnetic materials are presumably dumped in the area. The ferromagnetic objects of the refuse dump on the northern and downstream river course are presumably responsible for the magnetic closures across the stream in the area around Omosule Street and Oshinle Road.

Higher magnetic susceptibility values obtained on the flanks may be due to the presence of migmatite (a magnetic mineral). This is because migmatite appears to be present in the soils in higher proportion than other, more soluble minerals. Occurrence of migmatite in high proportion is obtainable in lateritic environment (Breiner, 1973) which is a major feature of the area of study. The higher the percentage composition of migmatite, the higher the magnetic susceptibility.

\section{CONCLUSIONS}

Terrain conductivity mapping and laboratory sampling of 21 water wells in Oluwatuyi/Oshinle area of Akure has been undertaken in this study to determine the level of contamination occasioned by ubiquitous refuse in the area. The higher conductivity values obtained from horizontal dipole measurements is indicative of level of upper strata contamination occasioned by leachates associated with massive refuse dump. The lower conductivity values obtained from vertical dipole measurements suggest low level contamination of the deeper strata due to overburden protection offered by abundant clay/sandy clay materials in the area. The similarity in conductivity distribution as seen from maps generated from field and laboratory measurements demonstrate that terrain conductivity is strongly influenced by fluid content.

The magnetic susceptibility values obtained from horizontal and vertical dipoles show close range of values on all flanks of the study area. The magnetic susceptibility closures of the northern course of River Elegbin enabled the delineation of dumped massive 
ferromagnetic objects (drums, cans, tins and disused vehicle parts) in the area. The low magnetic susceptibility contours characterizing the central and southern course of the stream enabled the classification of the refuse dump in the area to domestic type trash.

\section{REFERENCES}

Breiner, S., 1973. Applications Manual for Portable Magnetometer. Geometrics California, P. 8 \& 46-47.

Foster, A. R., Veatch, M. D. and Baird, S. L., 1987. Hazardous Waste Geophysics. The Leading Edge vol. 6 No. 8. 8-13.

Green, A., Lanz, E., Maurer, H. and Boerner, D., 1999. A Template for Geophysical Investigations of Small Landfills. The Leading Edge, 18(2): 248254.

Jones, H. A. and Hockey, 1964. The Geology of Southwestern Nigeria. G.N.S. Bull. No. $3187 p p$
Lanz, E., Boerner, D. E., Maurer, N. and Green, A., 1998. Landfill Delineation and Characterization, JEEG, 3(4): 185 - 196.

Olorunfemi, M. O. and Olorunniwo, M. A., 1985. Geoelectric Parameters and Aquifer Characteristics of some parts of Southwestern Nigeria. Geologia Applicata E. Idarogeologia Bari, Vol. xx, PP. 99-109.

Owoyemi, F. B., 1996. Updated geologic map of Akure, Ondo State. Unpublished M.Tech thesis. Dept. of Applied Geophysics, Federal Univ. of Technology, Akure.

Rahaman, M. A., 1976. Review of Basement Geology of South Western Nigeria: Geology of Nigeria, Elizabethan Publishing Co., Nigeria PP. 41-58.

Vickery, A. C. and Hobins 1998. Contributions of Surface Geophysics to Environmental Site Investigation of Former Oil Distribution Terminals JEEG, 3(3): 107-109. 